\title{
A cidade e seus temas relatos de uma trajetória exemplar
}

\author{
CIBELE SALIBA RIZEK
}

RESUMO: O texto resenha Escritos Urbanos, de Lúcio Kowarick (São Paulo, Editora 34, 2000).

cidades, espoliação urbana, lutas urbanas.

Professora do Departamento de Arquitetura e Urbanismo da Escola de Engenharia de São Carlos - USP 
têm um alcance explicativo e teórico muito maior: pulsam pelos temas, análises e descrições urbanas dimensões críticas que também iluminam processos, formas de estruturação econômica, social e política, esferas de determinação e esferas que pertencem à ação, aos sentidos, às subjetividades. Pulsa, sobretudo, uma noção especialmente fértil de conflito, tal como se territorializam no tecido urbano. Assim, mesmo nas dimensões obviamente econômicas da pobreza e de sua espacialização urbana, é possível enxergar as dimensões políticas tanto do conflito e de sua legitimidade quanto dos modos pelos quais ele foi deslocado ou silenciado.

Trata-se, então, de perceber que a cidade e a experiência da cidade não podem ser reduzidas ou deduzidas das lógicas da acumulação, da dinâmica econômica das formas de reprodução do capital e da força de trabalho. Desta forma, se a espoliação urbana, "convém insistir", decorre "do processo de acumulação do capital mas também da dinâmica das lutas e reivindicações em relação ao acesso à terra, habitação e bens de consumo coletivo", estes mesmos processos permitem que se divise, afirma Lúcio Kowarick, que "o papel do Estado é fundamental, não só pelas razões já arroladas, mas também porque o investimento que injeta no tecido urbano é fator de intensa valorização diferencial da terra, aparecendo como ator importante no processo de especulação imobiliária e segregação social" (Kowarick, 2000, p. 23). A partir destes elementos e da sua complexa relação, o primeiro capítulo aponta vínculos, transitividades, formas de visibilidade, movimentos da fábrica e do bairro, anunciando o que viria a se tornar um tema central para os anos 90: o tema da cidadania civil e social e seu correlato negativo, a subcidadania.

Neste primeiro texto, escrito há mais de uma década, mas republicado em 2000, reapresenta-se a questão do Estado como elemento sem o qual não é possível compreender as cidades e os modos pelos quais são vividas por seus habitantes. As formas de moradia da população de baixa renda, a precariedade da vida, a auto-construção em seus vínculos com as formas de acumulação e reprodução do capital nas metrópoles do subdesenvolvimento industrializado, fazem ecoar origens e modos de reflexão que ainda falam do que são as cidades brasileiras e, ao mesmo tempo, do que é a Região Metropolitana de São Paulo e, nela, as desigualdades e a segregação sócio-espacial.

Territórios constituídos por processos socioeconômicos, seus desdobramentos e mediações políticas são percorridos através dos temas que enunciam matrizes teóricas e temáticas através das quais a cidade e seus problemas são postos em questão.

Neste primeiro capítulo, pode-se entrever ainda alguns dos diálogos teóricos bem como seus lugares de interlocução. Um conjunto de temas que conformam o que Lúcio Kowarick chamou de espoliação urbana se ancora nas discussões que fundam parte da reflexão brasileira e paulista dos anos 70. Ecoam no texto os temas da dependência, a tentativa de compreensão de circuitos e formas de acumulação, as questões geradas 
pela discussão da marginalidade, sem dúvida uma leitura d'O capital, levada a cabo no âmbito do Centro Brasileiro de Análise e Planejamento (CEBRAP), alguns dos temas clássicos que forjaram parte da literatura das ciências sociais no Brasil.

Os elementos que combinavam crítica e teoria marxista à discussão das especificidades brasileiras e às possibilidades de desenvolvimento, o então chamado setor informal e, finalmente, a insólita combinação entre crescimento e pobreza no pólo dinâmico da industrialização brasileira (cf.Kowarick, 1976) aos poucos se misturam a outras interlocuções. Jovens pesquisadores, tais como Silvio Caccia Bava, Vera da Silva Telles, Nabil Bonduki (que aliás escreve a orelha do livro) vão desenhando lutas sociais e seus vínculos com a cidade e apontando para um outro lugar de enunciação teórica e de crítica, um lugar em que novas interrogações e seus desdobramentos de pesquisa se estabelecem. Mais uma vez, a compreensão das formas de sociabilidade urbana escapa dos argumentos que as reduzem a um efeito ou reflexo ou à pura materialização das lutas de classe nos espaços fabris. Ressoam assim, neste primeiro capítulo, os temas de um livro, que também se organizou a partir dessas interlocuções generosas entre uma reflexão madura e um conjunto de inquietações e temas de investigação de teses e dissertações. Entre os muitos argumentos de um texto que testemunha estas interrogações, Kowarick pontua o que a forma urbana das relações sociais em São Paulo trouxe como problema de investigação:“...creio ser falaciosa a afirmação segundo a qual as lutas desenvolvidas nos bairros serviram apenas para paralisar as máquinas (...) as aglutinações urbanas tiveram impacto social e político não desprezível, como atestam as inúmeras reivindicações em torno das melhorias por transporte, água, esgoto, creches e outros bens básicos para a vida nas cidades" (Kowarick, 2000, p. 37). A partir da cidade e da experiência metropolitana, elaborava-se uma consciência da exclusão, um campo de resistência e organização popular, uma consciência da insubordinação, ações de desobediência civil, ou seja, vinculam-se os temas da cidade e da espoliação urbana e da cidadania e suas lutas e desventuras.

Temas e conceitos, ancorados na noção thompsoniana de experiência, vão dando continuidade a uma leitura crítica que politiza a cidade nas figuras do subcidadão urbano e nas formas pelas quais ele é descrito e enunciado, o que fertiliza e atualiza as dimensões do contraponto entre risco e segurança, entre ordem e desordem. Kowarick reencontra, então, temas clássicos que atravessaram a reflexão brasileira ancorando-os na cidade. Ordem e desordem ganham visibilidade por meio das formas pelas quais a desigualdade se dá a perceber e se faz experimentar, ou seja, das formas pelas quais a cidade vai sendo esquadrinhada por uma atualização do discurso e do imaginário da ordem e do controle contra o resíduo que ganha rosto: "de tez morena ou escura, mal vestido de aparência subnutrida. De preferência não porta ou não tem carteira de trabalho e mora nos cortiços das áreas centrais ou nas favelas das periferias" (Kowarick, 2000, p. 54). Ordem, imaginário da ordem e vio- 
lência, descritas através das formas e da experiência da desigualdade documentam processos que constituem a fisionomia das cidades brasileiras e da Região Metropolitana de São Paulo, em particular. Os dados discutidos no texto apontam os destinos da cidade entre os anos 80 e 90. Na "São Paulo de 1987 havia 813 mil favelados, montante que em 1993 sobe para 1,9 milhões de pessoas. Para se ter uma idéia desse explosivo crescimento, basta dizer que mais de dois terços dos novos habitantes desse período avolumaram-se nas favelas..." (Kowarick, 2000, p. 46).

Na contramão dos horizontes de emancipação que perdem força e legitimidade e do reconhecimento dos conflitos que desenham seu território, afirma-se uma ordem, econômica por certo, mas também política, de caráter estreito e excludente, uma ordem que separa e segrega conferindo visibilidade às classes perigosas e às formas da violência.

Os capítulos 3 e 7 conformam-se a partir de alguns eixos que põem às claras a dimensão continental da cidade como questão. O leitor que acompanhou alguns dos debates mais marcantes da investigação e da reflexão teóricas brasileiras, certamente reconhecerá aqui algumas das interlocuções e dos interlocutores que enunciaram suas inquietações nos mesmos termos, em busca de análises que conferissem um caráter continental para a discussão dos territórios urbanos e dos processos macro sociais de desenvolvimento. Nun, Quijano, Casanova, mas também Caltells, além da referência a Topalov, montam um quadro de diálogos que se fazem sentir no terceiro capítulo de modo mais direto. Uma das ênfases mais importantes deste texto recai sobre as formas e usos da cidade, simultaneamente como reivindicação, movimento popular e lutas urbanas, por um lado e, ao mesmo tempo, como forma e terreno a partir do qual a dominação podia ser legitimada. A questão do estado ganha mais uma vez uma posição central, não apenas do ponto de vista dos mecanismos de espoliação urbana, mas como alvo de conflitos e de lutas, como instância contra a qual estes conflitos talvez pudessem ser politizados e como ator com poder de persuasão, fragmentação, controle, repressão, desmobilização das iniciativas populares e de classe pela extensão da cidadania que passa, afirma Kowarick, "cada vez mais pela questão urbana" (Kowarick, 2000, p. 66).

O capítulo intitulado Os caminhos do encontro talvez apresente de modo mais claro um ponto de inflexão que já se fazia sentir desde o primeiro capítulo, já que coloca no centro de suas inquietações a noção de experiência. Este texto, difícil de ser encontrado antes da publicação destes Escritos, é um testemunho dos anos 80, de suas especificidades brasileiras. Testemunha também muitas das esperanças que tornavam mais amena a experiência de uma década perdida do ponto de vista do crescimento e desenvolvimento econômico, mas fértil do ponto de vista da emergência dos conflitos e de sua politização. Autores como Vera da Silva Telles, Eder Sader (Sader, 1988 e Telles, 1987), Tilman Evers, e outros que analisaram os movimentos sociais como "novos personagens" ou "novos sujeitos", vão ganhando densidade, ao longo do texto. A crítica da lógica genéticofinalista aponta também para uma outra concepção que começava a ganhar terre- 
no: tanto as experiências de classe quanto os movimentos sociais eram mais do que personificações de categorias, mais (e menos) do que encarnações de conceitos e estruturas; sua história e seu alcance não poderiam mais ser amarradas, no tempo e no espaço, a uma "história natural dos acontecimentos" (Kowarick, 2000, p. 70). Necessidades e direitos, esferas invisíveis de conflito e produção de acontecimentos decisivos na história da redemocratização do país, ganham forma e vão sendo perceptíveis nos territórios das cidades, especialmente em São Bernardo e no ABC paulista; tornam-se visíveis em seu fazer-se, para retomar a clássica expressão de E. P. Thompson.

Uma outra questão decisiva configura-se ainda no âmbito deste texto: Os caminhos do encontro entre a experiência do trabalho e a de moradia, seus "pontos de fusão" que potencializam, quando e se acontecem, conflitos e reivindicações ${ }^{1}$. Este é um dos veios que o levam ao encontro das formas pelas quais cidades e experiência do trabalho são apreendidas e enunciadas teórica e metodologicamente. Inquirindo a possibilidade e a visibilidade destes encontros e fusões entre conflitos e reivindicações, assim como a territorialidade das relações que produziram alguns dos mais importantes acontecimentos políticos da história da redemocratização do país, Lúcio Kowarick observa:

"Talvez não seja arriscado afirmar que - malgrado a dispersão e a fragmentação dos conflitos que permanecem em âmbitos parciais, deixando de adicionar amplas e variadas esferas reivindicativas - os pesquisadores foram treinados para captar o que há de estanque e parcializado, e têm grandes dificuldades teóricas e metodológicas para perceber e compreender que o movimento real das lutas se intercruza muitas vezes de maneira pouco perceptível (...) Não se trata, obviamente, de fazer uma fusão no plano da teoria para cobrir ou encobrir o que inexiste na realidade, mesmo porque a (des) articulação e a (des) união de cada luta concreta e, sobretudo, de suas somatórias é algo que decorre da oposição de forças sociais. (...) Falta ainda muito esforço teórico e de pesquisa para se obter instrumentos conceituais adequados, que dêem conta da problemática referente à ligação entre exploração do trabalho e espoliação urbana, que, como já apontado nos capítulos iniciais, só por razões de facilidade analítica podem ser abordadas de maneira separada” (Kowarick, 2000, p. 77).

No quinto capítulo, os temas da cidade e de suas exclusões já se apresentam nos termos das discussões permeadas pelas noções de espaço público e privado, de cidadania e subcidadania, que se conformarão em uma das tônicas dos anos 90. Este texto se vincula, como o autor aponta, a alguns resultados de pesquisa desenvolvida no CEDEC - Centro de Estudos de Cul-
1 Deste ponto de vista é sempre bom lembrar que as dimensões do trabalho e de sua história também se fizeram presentes na obra de Lúcio Kowarick, a partir dos temas da marginalidade e informalidade, assim como do processo de sua gênese histórica. O trabalho e seu avesso a vadiagem - a longa e difícil transformação que constituiu o trabalhador livre e disciplinado, habitaram sua obra. Ver, neste sentido, Kowarick (1975) e (1987). 
tura Contemporânea -, intitulada Modo e condição de vida: uma análise das desigualdades sociais na Região Metropolitana de São Paulo. Achados de pesquisa e dimensões teóricas apontam para o diagnóstico de um universo de desigualdades, identidades e marcos simbólicos que apontam para uma cidadania construída de modo privado, no contexto das metrópoles do subdesenvolvimento industrializado. Cidadãos privados, porque ocultos e isolados, em espaços públicos eminentemente excludentes e violentos marcam as formas da sociabilidade política brasileira e, por conseqüência, as formas de sociabilidade que ganham corpo nas cidades. Cidadãos que se definem como não cidadãos, espaços públicos que mal podem ser concebidos como tal, projetos e marcos simbólicos em crise, este texto traz a marca de uma promessa que não se cumpriu nem pelo lado das lutas contra a exploração, tampouco pelo lado das reivindicações urbanas. Nos modos e condições de vida na cidade, outros fenômenos se fazem visíveis nos marcos simbólicos da "autoconstrução de uma percepção de moralidade e dignidade" que "tende a se solidificar nos valores e símbolos em torno de projetos individuais" (Kowarick, 2000, p. 95). Nesta constatação, Lúcio Kowarick parece estar em outro terreno, marcado pela individualização e privatização da experiência e distante dos territórios da ação coletiva que apontavam para as reivindicações urbanas contra a espoliação e para as lutas contra a exploração.

Fatias de nossa história recente, o sexto capítulo do livro, é um exercício reflexivo. Identificam-se caminhos e interlocuções e, sobretudo, mapeia-se um campo de discordâncias que permite que se recuperem argumentos e contrapontos. Desta perspectiva, mais do que fatias, este capítulo esclarece o percurso intelectual do autor com lucidez e serenidade, perseguindo cada noção, explicitando os debates nos quais cada conceito foi formulado. A recuperação deste percurso entrelaça gerações, lugares da produção de pesquisas e reflexão e sua história, as concepções e matrizes pelas quais a cidade e a vida urbana foram enunciadas, inserindo cada "fatia" na produção das ciências sociais no Brasil. Como um exercício de memória e de seu registro, este capítulo tem o sabor de uma produção madura que pode se debruçar sobre si. Ao rememorar esperanças e debates acadêmicos e políticos, faz lembrar de cada esperança, de cada utopia ao mesmo tempo que se inscreve de modo claro na tradição crítica de reflexão sobre as cidades brasileiras, entrelaçadas com as grandes questões que atravessam as ciências sociais no Brasil.

Chega-se, assim, ao último capítulo, já imerso nos temas da globalização e de suas conseqüências para as cidades latino-americanas. Tratase sobretudo de pensar através de que temas e por meio de que disposições teórico-metodológicas a pesquisa sobre as cidades poderá ou deverá prosseguir e se enriquecer. Os termos e os personagens em debate são explicitados assim como as formas de perceber os destinos e parâmetros presentes de investigação. Trata-se mais uma vez de um conjunto de discussões que, para além das decepções e promessas enunciadas no passado, aponta como hori- 
zontes a continuidade da investigação e da reflexão sobre a cidade que tem como horizonte possível um "ideário de uma concepção que se constrói a partir da luta da sociedade civil e que passa necessariamente, e cada vez mais, pela questão da democracia. Afinal de contas, é preciso continuar acreditando que Nuestra América tem armazenado enorme potencial ocioso de historicidade" (Kowarick, 2000, p. 134).

Esta fidelidade e persistência na busca de um horizonte que permita tanto a crítica quanto o avanço da pesquisa e da investigação, mesclada a um conjunto de interrogações que, ao tomar a cidade como objeto, pensa as grandes questões que marcam a reflexão brasileira, e ao enunciá-las as enraíza nas cidades, faz do percurso intelectual de Lúcio Kowarick muito mais do que um pensamento cujo escopo de validade e esforço heurístico se voltam para uma cidade - a cidade de São Paulo, presente em sua obra e nestes Escritos. Ao contrário, esta reflexão, que tem o conflito como noção central, sinaliza as matrizes e interlocuções recentes por que passou parte significativa dos embates entre investigação e sociabilidade urbana e política no Brasil. Afinal - retomando a frase de um livro que marcou os anos da ditadura militar brasileira - para os seus habitantes, "a cidade é um modo de existência" (Kowarick et alii, 1976).

Recebido para publicação em abril/2001

RIZEK, Cibele Saliba. The city and its themes: accounts of an exemplary path. Tempo Social; Rev. Sociol. USP, S. Paulo, 13(1): 229-236, May 2001.

ABSTRACT: This text is a review of Escritos Urbanos by Lúcio Kowarick (São Paulo, Editora 34, 2000).

cities, urban plunder, urban struggles.

\section{REFERÊNCIAS BIBLIOGRÁFICAS}

KowARICK, Lúcio. (1975) Capitalismo e marginalidade urbana na América Latina. Rio de Janeiro, Paz e Terra.

et alii. (1976) São Paulo 1975. Crescimento e pobreza. São Paulo, Edições Loyola.

. (1979) A espoliação urbana. Rio de Janeiro, Paz e Terra.

. (1987) Trabalho e vadiagem. A origem do trabalho livre no Brasil. São Paulo, Brasiliense. 
(org.). (1994) As lutas sociais e a cidade. São Paulo passado e presente. São Paulo, Paz e Terra. $2^{\text {a }}$. Edição.

. (2000) Escritos urbanos. São Paulo, Editora 34.

SADER, Eder. (1988) Quando novos personagens entram em cena. São Paulo, Paz e Terra.

TelLes, Vera da Silva. (1987) Movimentos sociais: reflexões sobre a experiência dos anos 70. In Warren, Ilse \& KrischKe, Paulo (orgs.). Uma revolução no cotidiano: novos movimentos sociais na América Latina. São Paulo, Brasiliense. 